\title{
Testing Individuals' Ability to Compare Emissions from Public Transport and Driving Trips
}

\author{
William Brazil, Brian Caulfield \\ Trinity College Dublin
}

\begin{abstract}
To make informed environmental choices, individuals must first understand the potential environmental impacts of the modes of transport available and be able to relate this information to their own internal reference points. This study examines the results of an on-line survey conducted to assess the ability of individuals in the Greater Dublin Area to estimate their potential carbon footprint for a variety of modes of transport. The results indicate that nearly one third of those surveyed stated that they simply did not know the carbon footprint of the modes in question, while those who provided emissions estimates showed a wide range of variance. Comparison with existing emissions factors indicates that respondents overestimate the environmental impact of bus journeys and underestimate the impact of small car and tram trips. The results of this study indicate the need for more specific emissions information to allow individuals to make informed and sustainable mode choices.
\end{abstract}

\section{Introduction}

Human economic activity is now recognized by the majority of scientists as a contributor to global climate change due to the emissions of greenhouse gases (GHGs) such as carbon dioxide (Bray 2010). In the Republic of Ireland, transport 
emissions are estimated to have accounted for 19 percent of total emissions produced for the period 2008-2012 (EPA 2012). While there is an apparent awareness among the population about the impact of their carbon emissions, there are also a number of barriers to the desired behavior change, including lack of knowledge about the benefits of sustainable transport (Browne et al. 2011; Lorenzoni et al. 2007). If individuals are to be able to make decisions with the aim of reducing their transport-related carbon footprint, they need to be sure that they are choosing the most sustainable alternatives available to them, such as public transport and nonmotorized modes. While there is an ever-increasing number of carbon footprint calculators available for a number of different technological platforms, offering comparisons between transport modes, it is still unclear to what extend these have educated the population with regard to carbon emissions, as these calculations are often far from consistent in terms of outputs (Kenny and Gray 2009). This study seeks to examine the ability of the general public to assign values and implicit rankings to the carbon emissions associated with driving and a number of different public transport modes available in the Greater Dublin Area (GDA) as defined by the National Transport Authority (NTA).

\section{Public Transport in Dublin}

The public transport system in Dublin is highly radial in nature and is centered upon the city center and Central Business District (CBD). The rise in low-density urban sprawl that accompanied the economic upturn, labeled the "Celtic Tiger," has resulted in a geo-spatial environment that is far from ideal in terms of the provision of public transport (Browne et al. 2011). Despite the construction of two new "Luas" tram lines and the upgrading of existing commuter rail services, large sections of the Greater Dublin Area remain accessible only by bus service. Existing bus networks are themselves highly radial, and service frequency levels vary widely across the network, leaving travelers certain areas of the GDA with little option but to drive (Caulfield 2012). This is reflected in recent census figures (Central Statistics Office 2012) which indicate the of the 529,812 residents Dublin making trips to work, 12.4 percent took bus, coach, or minibus and 7.5 percent took train or tram. In contrast, 49.2 percent stated that they drove to work, and this figure rises to 55.5 percent when accounting for car passengers and commercial vehicles. When compared to the Irish governments policy targets (DoT 2009) of a 20 percent reduction in car commuter trips nationally and the majority of the commuter trips being undertaken using sustainable modes, it is clear that significant behavior change is needed with regard to utilizing existing public transport. 


\section{Survey Methodology}

The research questions discussed in this paper formed part of wider study concerning carbon dioxide emissions and transport choices in the Greater Dublin Area. An online questionnaire $(n=503)$ was distributed to a number of large public sector institutions, including municipal councils and government departments, in November and December 2012. Special attention was paid to ensure that organizations outside the CBD were included to capture suburb commutes, as these are likely to be very different from those anchored in the CBD. Table 1 outlines the demographic characteristics of the sample. Partly as a consequence of the distribution methods employed, the sample is over-representative of younger individuals and those with higher levels of education. As this survey was conducted online, some respondents failed to provide demographic information; however, this was not deemed an adequate reason to eliminate their estimates from the analysis.

Table 1. Sample Properties

\begin{tabular}{|c|c|c|c|c|c|c|}
\hline \multirow{2}{*}{ Gender } & Male & Female & $N^{*}$ & & & \\
\hline & $42.8(34.8)$ & $57.2(46.5)$ & 18.7 & & & \\
\hline \multirow{2}{*}{ Age } & $15-24$ & $25-34$ & $35-44$ & $45-54$ & $55+$ & NA \\
\hline & $15.7(12.3)$ & $25.5(20.1)$ & $24.7(19.5)$ & 25 (19.7) & $9.1(7.2)$ & (21.3) \\
\hline \multirow[t]{2}{*}{ Education } & $\begin{array}{l}\text { High } \\
\text { school }\end{array}$ & Diploma & $\begin{array}{c}\text { Bachelor's } \\
\text { degree }\end{array}$ & $\begin{array}{l}\text { Higher } \\
\text { degree }\end{array}$ & NA & \\
\hline & $25.4(20.5)$ & $17.7(14.3)$ & $22.9(18.5)$ & $34(27.4)$ & $(19.3)$ & \\
\hline \multirow{2}{*}{ Income } & $€ 0-24 K$ & $€ 25-49 \mathrm{~K}$ & $€ 50-74 \mathrm{~K}$ & $€ 75-99 \mathrm{~K}$ & $€ 100 k+$ & NA \\
\hline & $22.2(17.9)$ & $44.6(36)$ & 20.9 (16.9) & $6.4(5.2)$ & $2(1.6)$ & (22.5) \\
\hline
\end{tabular}

*NA = no answer

\section{Environmental Attitudes}

As part of this survey, respondents were asked to give their opinions on a number of statements regarding their existing attitudes towards climate change and transport. The results in Figure 1 show that the majority of respondents agree that climate change is occurring and is a serious issue, and they have a personal responsibility in this area. 
I should lower my carbon footprint even if I have to suffer financially

I believe that I should change my transport habits to reduce my carbon footprint

I have a personal responsibility to reduce my carbon footprint

I believe that global warming is one of the most serious challenges faced humanity

I believe that global warming is occurring

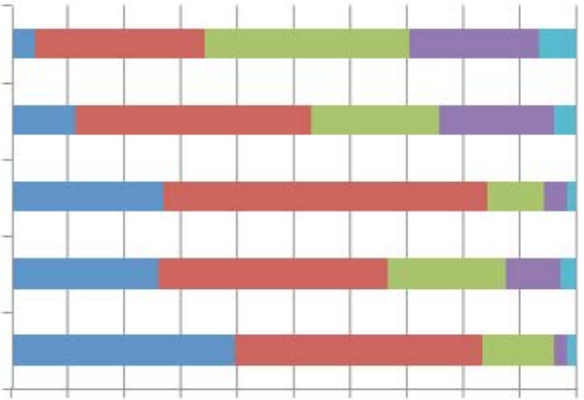

$0 \% \quad 10 \%$ 20\% 30\% 40\% 50\% 60\% 70\% $80 \%$ 90\% $100 \%$

Wtrongly Agree Agree Undecided Disagree $\quad$ Etrongly Disagree

\section{Figure 1. Attitudes towards climate change}

\section{Access to Sustainable Transport}

While it appears that there is concern and appreciation of the need to take action with regard to transport behavior, there were also a number of barriers indentified that prevent the necessary changes from occurring. The uneven geographical distribution of environmentally-friendly alternatives, alluded to previously, was reflected in the results of the respondents' perceived access to sustainable modes. Figures 2 and 3 indicate that perceived access to sustainable transport for both work/educational trips and non-work/educational trips declines with respect to distance of the respondents' homes from the city center. The issue of access to sustainable modes of transport becomes more acute as the length of commuting journeys increases with respect to distance from the city center. As journey length is a major factor in terms of the production carbon dioxide emissions, the result of this is that individuals produce much higher emissions in rural areas (McNamara and Caulfield 2011). 


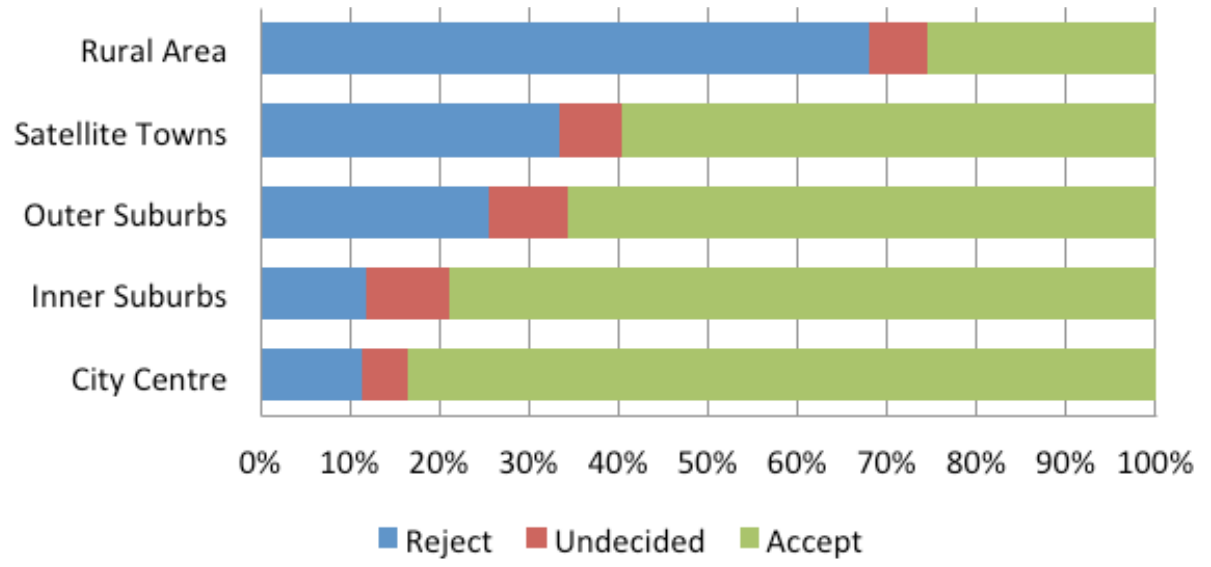

Figure 2. Access to sustainable transport vs. residence (commuting/educational trips)

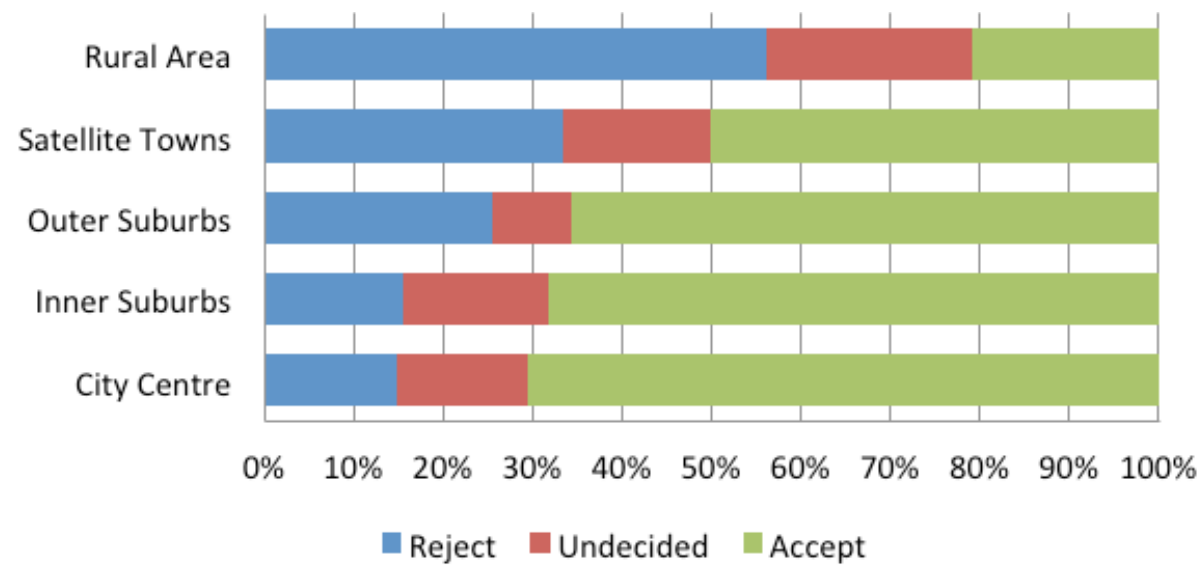

Figure 3. Access to sustainable transport vs. residence (non-commuting/educational trips)

\section{Informed Decisions}

Among the questions posed to respondents was the statement, "I have enough information to make informed transport choices." The responses displayed in Figure 4 indicate that the majority of respondents believe this to be true, with less than 20 percent disagreeing. However, due to concerns regarding the capacity of 
individuals to assess their own abilities highlighted in the literature (Whitmarsh et al. 2011; Lorenzoni et al. 2007) and issues such as self report bias and social desirability bias, it was decided to test this assertion further.

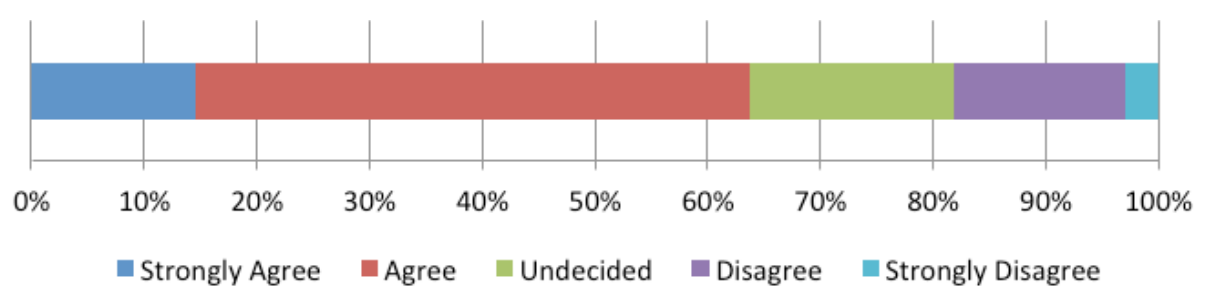

\section{Figure 4. "I have enough information to make informed transport choices"}

\section{Testing Emissions Knowledge}

While respondents may have been of the opinion that they are able to make informed choices with regard to sustainable transport options, this would appear to contradict findings from the literature (Whitmarsh et al. 2011; Gadema and Oglethorpe 2011). Carbon dioxide emissions have a number of specific features that make them harder to relate to than other aerosol pollutants. Carbon dioxide is both colorless and odourless, and emissions may be produced at a distance, both in terms in time and space, from the individual who benefits from the related economic activity. A prime example in public transport is the tram system in Dublin. The tram itself does not produce any emissions directly, as it is powered electrically. However, due to its operation, a large amount of electricity energy must be used, the majority of which is produced from fossil fuels (Howley 2009). To test this hypothesis, respondents were asked to estimate how much $\mathrm{CO}_{2}$ six different modes would emit for a $10 \mathrm{~km}$ journey. The six modes considered for this experiment were:

- Small car (defined as less than $1.6 \mathrm{~L}$ )

- Large car (defined as $1.6 \mathrm{~L}+$ )

- Tram (light rail system operating in the Greater Dublin Area)

- Heavy rail (DART/suburban rail system operating in the Greater Dublin Area)

- SUV (sports utility vehicle)

- Bus 
These modes represented the majority of trips undertaken in the GDA (Central Statistics Office 2012). The decision to provide respondents with three driving options was due to the large proportion of trips accounted for by this mode (Gormley 2011). It is also important to consider that there are individuals who do not have access to sustainable modes of transport and, therefore, their only option, with respect to emissions reduction, may be to switch to car models with lower emissions ratings. Electric vehicles were omitted, as they are still uncommon in Dublin, and the emissions arising from non-motorized modes (Walsh et al. 2008) were not assessed, as it was felt that this may confuse respondents.

Although it could be possible that it that individuals may not possess knowledge of the precise emissions related to their trips, the format of the question allowed modes to be ranked in relation to one and another, in terms of associated carbon dioxide emissions.

The decision to present the respondent with categories that were non-uniform in size was due to the wide range in emissions that are related to different modes. As the average emissions of a mode increases, so does the range of values across which any given measurement may fall, resulting in a heteroscedastic pattern of possible emissions values.

The categories were intended to capture, as much as possible, the range into which modes were likely to fall-i.e., car trips usually fall between $1 \mathrm{~kg}$ and $5 \mathrm{~kg}$ and Luas tram trips between $250 \mathrm{~g}$ and $1 \mathrm{~kg}$ (Walsh et al. 2008). Figure 5 displays the question interface that was presented to respondents as part of the survey. It clearly indicates that emissions are per passenger, rather than for the vehicle as a whole.

For a 10 kilometre journey, how much carbon dioxide do you think the following modes of transport would emit
Note: You can pick the same emissions for different modes of transport
All emissions are PER PASSENGER
Small Car less than $1.6 \mathrm{~L}$
Large Cat 1.6L.
Luas
nART/Suburban Rail
SUV
Bus

Figure 5. Emissions test 


\section{Results}

\section{Emissions Estimates}

Table 2 displays the percentage of respondents who simply stated that they did not know the emissions associated with each mode. This represents roughly one third of overall respondents. This finding, in itself, indicates that a sizable proportion of the population is simply unable to provide any type of estimate, or even guess, regarding their transport emissions. As the question was presented in the first section of the survey, we can discount the influence of survey fatigue. For the rest of the paper, analysis was performed on only the respondents that provided emissions estimates (henceforth known as "participants"). It was found that the vast majority of individuals who stated that they did not know for any given mode also failed to provide estimates for any of the other modes. Therefore, it was decided to consider all emissions estimates provided for the purpose of further analysis.

Table 2. "Don't Know"

\begin{tabular}{|l|c|c|c|c|c|c|}
\hline & Small Car & Large Car & SUV & Bus & Tram & Heavy Rail \\
\hline Don't Know & $32 \%$ & $32.6 \%$ & $32.6 \%$ & $32 \%$ & $32.4 \%$ & $33.5 \%$ \\
\hline
\end{tabular}

Figure 6 displays the distribution of the participants' emissions selections for each of the modes under consideration. It is clear that participants, on average, assign higher emissions values to Large Cars and SUV than to public transport modes such as Bus and Heavy Rail (DART). It is also clear that the Tram option is the mode associated with the lowest emissions estimates. 


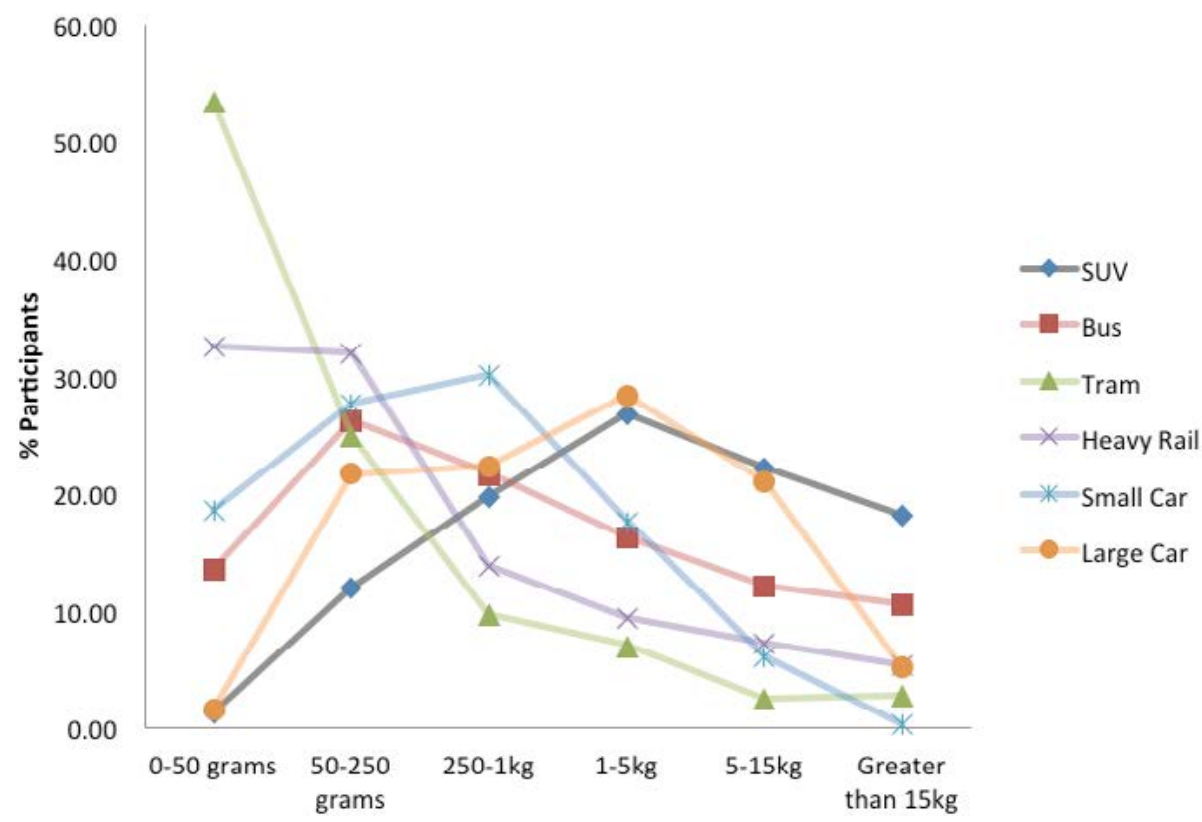

Figure 6. Participants vs. emissions estimates

Whereas Figure 6 presents the aggregate absolute category selection of respondents, it is also important consider the perceived relative position of modes in terms of associated carbon emissions. When an individual is faced with a decision between modes based upon his/her environmental impact, it may not be important that he/she is aware of the absolute emissions related to each mode, rather that he/she is able to recognize the differences in scale between the emissions associated by the available options. Acknowledging the need to assess relative emissions placement, Figure 7 presents the results of emissions comparisons between modes. Using the ordinal values assigned to categories in Table 3, it is possible to assess the aggregate "distance" between emissions estimates. For example, if an individual placed Small Car emissions in Category 4 and SUV emissions in Category 6 , the distance between these estimates is +2 . For results presented in Figure 7 , positive values relate to higher estimates and negative values to lower relative estimates. For example, it can be observed that aggregate estimates place SUV higher and Tram lower than all other modes and that the Bus option has higher associated emissions relative to the Small Car option. 
Comparisons with Small Car

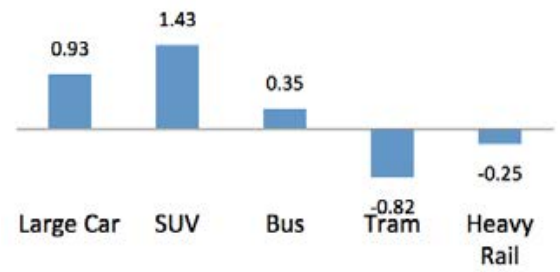

Comparisons with SUV

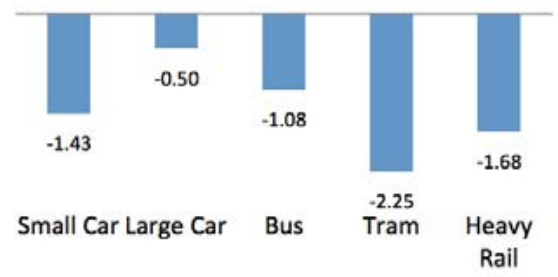

Comparisons with Tram

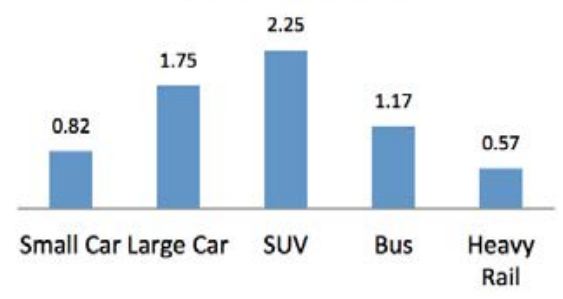

Comparisons with Large Car

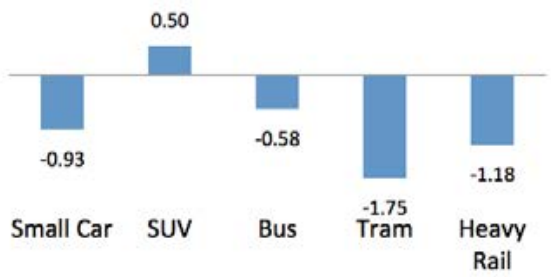

Comparisons with Bus

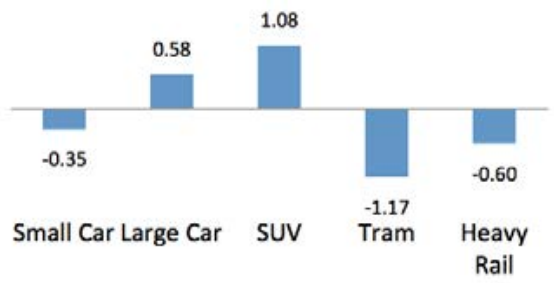

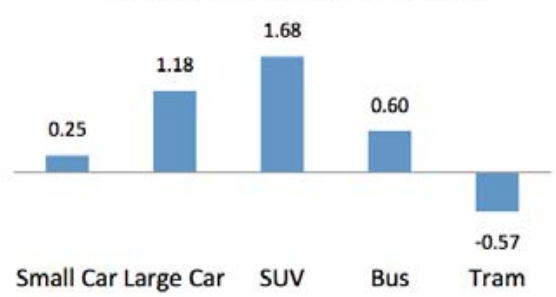

Figure 7. Mode comparisons

Table 3. Assignment of ordinal values

\begin{tabular}{|l|c|c|c|c|c|c|}
\hline Category & $\mathbf{0 - 5 0 g}$ & $\mathbf{5 0 - 2 5 0 g}$ & $\mathbf{2 5 0 g - 1} \mathbf{k g}$ & $\mathbf{1 - 5} \mathbf{k g}$ & $\mathbf{5 - 1 5 k g}$ & $>\mathbf{1 5} \mathbf{~ k g}$ \\
\hline Ordinal Value & 1 & 2 & 3 & 4 & 5 & 6 \\
\hline
\end{tabular}

As the emissions estimates were bound by the need to acknowledge real-world conditions, where modes have emissions ranges rather than definitive values, and where it is possible that these ranges overlap, the respondent selections cannot be treated as ranked data. Within the sample, 161 distinct relative emissions ordering 
patterns were observed, with none occurring more than 20 times. Further analysis of mode ranking with respect to emissions factors is presented in the next section.

\section{Accuracy of Estimates}

It was deemed important to provide a comparison with the participants' estimates and current emissions estimates for the Greater Dublin Area. Using the emissions values put forward by Walsh et al. (2008) concerning carbon emissions produced by transport modes in Ireland, it is possible to conduct a comparison between the participants' estimates and existing emissions factors. Values for Small Car and Large Car are taken as falling between $1-5 \mathrm{~kg}$. Walsh et al. (2008) gives a value of 0.120 per passenger for general cars in "normal" conditions. The United Kingdom's Transport Direct website (Transport Direct, accessed 2013) carbon calculator gives a small car value of $1.3 \mathrm{~kg}$ for a $10 \mathrm{~km}$ journey, and Transport for Scotland (Traffic Scotland, accessed 2013) gives a value of $1.7 \mathrm{~kg}$ for a petrol car with an engine capacity of below 1.4 litres, so we can assume that both car categories are likely to fall within the $1-5 \mathrm{~kg}$ range.

Tables 4, 5, and 6 indicate the categories into which each respective mode is most likely to fall and, based upon this, how accurate the participants' estimates were. To account for variances in per-passenger carbon emissions with regard to vehicle occupancy, the results were presented for modes at both average and full occupancy. Results assuming average vehicle occupancy are displayed in Table 4, and Table 5 presents the results associated with maximum occupancy. The adjusted results displayed in Table 6 represent a summation of the correct selections from the two categories and takes into account the respondents who stated that they were unable to assign values to the modes.

Table 4. Assuming Average Emissions Values

\begin{tabular}{|l|c|c|c|c|c|c|}
\hline & $\begin{array}{c}\text { Small } \\
\text { Car (Av) }\end{array}$ & $\begin{array}{c}\text { Large } \\
\text { Car (Av) }\end{array}$ & $\begin{array}{c}\text { SUV } \\
(\mathbf{A v})\end{array}$ & $\begin{array}{c}\text { Bus } \\
(\mathbf{A v})\end{array}$ & $\begin{array}{c}\text { Luas } \\
(\mathbf{A v})\end{array}$ & $\begin{array}{c}\text { DART } \\
(\mathbf{A v})\end{array}$ \\
\hline Emissions & $1.2 \mathrm{~kg}$ & $1.5 \mathrm{~kg}$ & $1.8 \mathrm{~kg}$ & $0.35 \mathrm{~kg}$ & $0.8 \mathrm{~kg}$ & $0.29 \mathrm{~kg}$ \\
\hline Category & $1-5 \mathrm{~kg}$ & $1-5 \mathrm{~kg}$ & $1-5 \mathrm{~kg}$ & $250-1 \mathrm{~kg}$ & $250-1 \mathrm{~kg}$ & $250-1 \mathrm{~kg}$ \\
\hline$\%$ Correct & $17.1 \%$ & $31.1 \%$ & $27.1 \%$ & $21.9 \%$ & $10.3 \%$ & $15.1 \%$ \\
\hline
\end{tabular}


Table 5. Assuming Maximum Occupancy Emissions

\begin{tabular}{|l|c|c|c|c|c|c|}
\hline & $\begin{array}{c}\text { Small Car } \\
(\text { Max })\end{array}$ & $\begin{array}{c}\text { Large Car } \\
(\text { Max })\end{array}$ & $\begin{array}{c}\text { SUV } \\
(\text { Max })\end{array}$ & $\begin{array}{c}\text { Bus } \\
(\text { Max })\end{array}$ & $\begin{array}{c}\text { Luas } \\
\text { (Max) }\end{array}$ & $\begin{array}{c}\text { DART } \\
\text { (Max) }\end{array}$ \\
\hline Emissions & $\sim 0.4 \mathrm{~kg}$ & $\sim 0.5 \mathrm{~kg}$ & 0.68 & 0.16 & 0.64 & 0.11 \\
\hline Category & $250-1 \mathrm{~kg}$ & $250-1 \mathrm{~kg}$ & $250-1 \mathrm{~kg}$ & $50-250 \mathrm{~kg}$ & $250-1 \mathrm{~kg}$ & $50-250 \mathrm{~g}$ \\
\hline$\%$ Correct & $29.9 \%$ & $19.3 \%$ & $20 \%$ & $29.1 \%$ & $10 \%$ & $32.3 \%$ \\
\hline
\end{tabular}

Table 6. Adjusted Accuracy

\begin{tabular}{|l|c|c|c|c|c|c|}
\hline & Small Car & Large Car & SUV & Bus & Luas & DART \\
\hline Sum & $47 \%$ & $50.4 \%$ & $47.1 \%$ & $50 \%$ & $10 \%$ & $47.4 \%$ \\
\hline Adj. & $32 \%$ & 33.4 & $31.7 \%$ & $34 \%$ & $6.8 \%$ & 31.5 \\
\hline
\end{tabular}

For most modes, participants displayed an accuracy rate of 45-50 percent, which when adjusted for all respondents corresponds to a 30-35 percent rate. The most striking result appears to be with regard to the accuracy of Tram estimates, with only than 10 per cent of participants correctly estimating its associated emissions, even when both occupancy levels are assumed.

Treating both average and maximum occupancy values as correct, it is possible to categorize the remaining selections as either underestimates or overestimates. Results displayed in Figure 8 clearly indicate that a large number of participants underestimated emissions for both Small Car and Heavy Rail. However, the most striking result is that 81 percent of participants underestimated the emissions associated with the Tram option.

In both the case of assuming average or maximum occupancy, a number of logical relationships emerge, such as all public transport modes having lower emissions than driving modes or all driving modes falling into the same category. The results in Table 7 indicate the percentage of participants that correctly identified the emissions relationships between modes. Perhaps the most striking result is that only 34.6 percent of participants correctly stated that all driving modes produce higher emissions than all public transport modes. This can be considered somewhat worrying from a public transport perspective, as it appears that individuals may not be aware of the potential emissions reductions associated with switching from driving. 


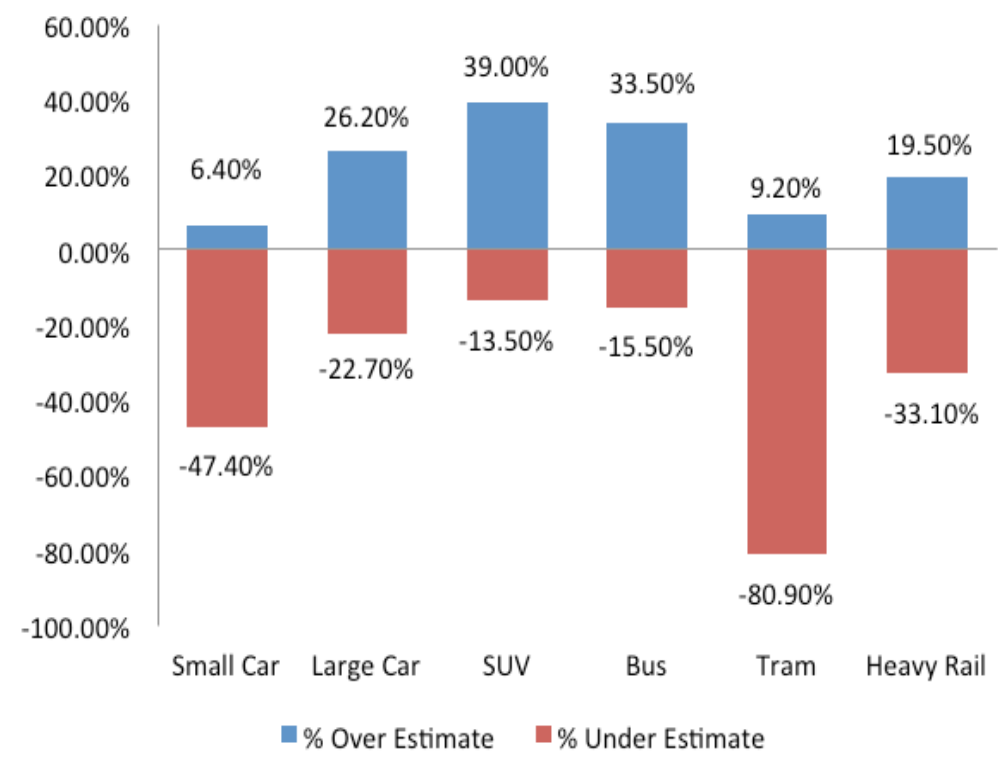

Figure 8. Underestimation and overestimation of emissions

Table 7. Comparisons

\begin{tabular}{|c|c|c|c|c|c|}
\hline $\begin{array}{c}\text { SUV= } \\
\text { Large Car }\end{array}$ & $\begin{array}{c}\text { SUV= } \\
\text { Small Car }\end{array}$ & $\begin{array}{c}\text { SUV> } \\
\text { Tram }\end{array}$ & $\begin{array}{c}\text { SUV> } \\
\text { Bus }\end{array}$ & $\begin{array}{c}\text { SUV> } \\
\text { Heavy Rail }\end{array}$ & $\begin{array}{c}\text { Large Car= } \\
\text { Small Car }\end{array}$ \\
\hline 110 & 26 & 226 & 163 & 197 & 46 \\
\hline $43.8 \%$ & $10.3 \%$ & $90 \%$ & $65 \%$ & $78.5 \%$ & $18.3 \%$ \\
\hline $\begin{array}{c}\text { Large Car } \\
>\text { Tram }\end{array}$ & $\begin{array}{c}\text { Large Car } \\
>\text { Bus }\end{array}$ & $\begin{array}{c}\text { Large Car } \\
>\text { Heavy Rail }\end{array}$ & $\begin{array}{c}\text { Small Car } \\
>\text { Tram }\end{array}$ & $\begin{array}{c}\text { Small Car } \\
>\text { Bus }\end{array}$ & $\begin{array}{c}\text { Small Car } \\
\text { >Heavy Rail }\end{array}$ \\
\hline 214 & 147 & 186 & 165 & 94 & 128 \\
\hline $85.2 \%$ & $58.5 \%$ & $74.1 \%$ & $65.7 \% \%$ & $37.4 \%$ & $50.9 \%$ \\
\hline Bus=Tram & Bus & $\begin{array}{c}\text { Tram } \\
>\text { Heavy Rail }\end{array}$ & All Cars Equal & $\begin{array}{c}\text { All Cars } \\
>\text { All PT }\end{array}$ & All Correct \\
\hline 73 & 123 & 12 & 20 & 87 & 0 \\
\hline $29 \%$ & $49 \%$ & $4.8 \%$ & $7.9 \%$ & $34.6 \%$ & $0 \%$ \\
\hline
\end{tabular}

\section{Conclusions and Discussion}

The results of the attitudinal statements contained in this research, presented in Figure 1, indicate that there is widespread recognition that climate change is a serious problem and that individuals acknowledge that they have personal responsibility with regard to tackling this issue. There are a number of barriers in terms 
of changing transport behavior, including perceived lack of access to sustainable modes with respect to residential location. While public transport offers a realistic sustainable alternative to a considerable proportion of the population, this is tempered by the inability of respondents to make accurate estimates concerning the impact of their transport choices.

The results of the examination of emissions knowledge indicate that a minority of the population has a good knowledge of the carbon dioxide emissions associated with different modes of transport. Roughly one third of those surveyed stated that they simply did not know the levels of emissions for each mode. This is in contrast to the stated ability of respondents to make informed transport choices. This indicates that not only are individuals unable to make accurate comparisons between available modes, they are also overly confident of their own abilities.

For those respondents who did answer, the overall carbon footprint of public transport modes was estimated to be less than driving. Tram and heavy rail were estimated to produce fewer emissions than any driving categories; however, bus journeys were viewed as falling with the same categories as driving.

The environmental impact of small cars was underestimated suggesting that individuals may be of opinion that switching to a smaller car may be an effective method of reducing their carbon footprint, whereas substantial reductions can occur via only mode change. The environmental impact of the tram system was also greatly underestimated, while the carbon emissions attributed to buses were overestimated. One potential explanation for this is that the tram system is relatively new and has no visible emissions, whereas buses produce visible emissions that may be confused with GHGs. It may also be the case that respondents were unable to understand the idea of per-passenger emissions rather than total vehicular emissions. However, this would also be of concern with regard to taking personal responsibility for transport emissions as individuals should be able to acknowledge their own personal contributions to climate change.

If individuals are to be asked to make sustainable personal transport choices, they must have the ability to make accurate comparisons with regard to the environmental impact of the modes available to them. In general, public transport modes were viewed as more sustainable than driving, with the exception of bus journeys. The overestimation of carbon emissions associated with bus journeys may result in individuals overlooking this mode as a sustainable alternative. 
This may be considered as an important research outcome, as individuals appear to be overestimating the environmental impact of the largest and most extensive public transport option in the Greater Dublin Area (Central Statistics Office 2012). The results of this study highlight that there is a need to provide better levels of education and information to transport users with regard to the environmental impacts of the alternatives available to them, in particular with regard to the city's bus network.

\section{Acknowledgments}

This work was sponsored by the PEACOX Project under the European Commission's Seventh Framework Programme (FP7).

\section{References}

Bray, D. 2010. The scientific consensus of climate change revisited. Environmental Science and Policy 13: 340-350.

Browne, D., B. Caulfield, and M. O'Mahony. 2011. Barriers to sustainable transport in Ireland. Prepared for the Environmental Protetcion Agency by Trinity College Dublin. Available at http://www.epa.ie/downloads/pubs/research/ climate/CCRP\%20Report\%20Series\%20No.\%207\%20-\%20Barriers\%20to\%20 Sustainable\%20Transport\%20in\%20Ireland.pdf.

Caulfield, B. 2012. An examination of the factors that impact upon multiple vehicle ownership: The case of Dublin, Ireland, Transport Policy 19: 132-138.

Central Statistics Office 2012. Profile 10 door to door. Dublin, Ireland.

Environmental Protection Agency (EPA). 2012. Ireland's greenhouse gas emissions projections 2011-2020. Wexford, Ireland.

Gadema, Z., and D. Oglethorpe. 2011. The use and usefulness of carbon labelling food: A policy perspective from a survey of UK supermarket shoppers. Food Policy 36: 815-822.

Gormely, N. 2010. Report on Dublin City Council's canal cordon traffic counts 2010. Available at www.dublincity.ie/RoadsandTraffic/Documents/7\%20Canal\%20 Cordon\%20Counts\%202010.pdf. 
Howley, M., B. Ó Gallachóir, and E. Dennehy. 2009. Energy in Ireland: Key statistics. Sustainable Energy Ireland. Energy Policy Statistical Suport Unit. Available at http://www.seai.ie/Publications/Statistics_Publications/EPSSU_Publications/ Energy_in_Ireland_Key_Statistics.pdf.

Kenny, T., and N. F. Gray. 2009. Comparative performance of six carbon footprint models for use in Ireland. Environmental Impact Assessment Review 29: 1-6.

Lorenzoni, I., S. Nicholson-Cole., and L. Whitmarsh. 2007. Barriers perceived to engaging with climate change amoung UK public and their policy implications. Global Environmental Change 17: 445-459.

McNamara, D., and B. Caulfield. 2011. Measuring the potential implications of introducing a cap and share scheme in Ireland to reduce green house gas emissions. Transport Policy 4: 579-586.

National Transport Authority. http://www.nationaltransport.ie/planning-policy/ planning-submissions/greater-dublin-area. Accessed February 25, 2013.

DoT (Department of Transport). 2009. Smarter travel policy framework document: A sustainable transport future. Government Stationery Office, Dublin, Ireland.

Transport Direct. $\mathrm{CO}_{2}$ Emissions Calculator. http://www.transportdirect.info/ Web2/JourneyPlanning/JourneyEmissionsCompare.aspx?\&repeatingloop=Y. Accessed February 25, 2013.

Traffic Scotland. $\mathrm{CO}_{2}$ Emissions Calculator. www.trafficscotland.org/ carboncalculator/A. Accessed February 25, 2013.

Walsh, C., P. Jakeman, R. Moles, and B. O'Reagan. 2008. A comparison of carbon dioxide emissions associated with motorised transport modes and cycling in Ireland. Transportation Research Part D 13: 392-399.

Whitmarsh, L., G. Seyfang, and S. O'Neill. 2011. Public engagement with carbon and climate change: To what extent is the public "carbon capable"? Global Environmental Change 21: 56-65. 


\section{About the Authors}

William BRAZIL (brazilw@tcd.ie) is a doctoral researcch student in the Department of Civil, Structural and Environmental Engineering Trinity College Dublin. His principal interests include provision of environmental information, the role of information in choice scenarios, and the role of behavioral economics within transport.

BRIAN CAULfield (brian.caulfield@tcd.ie)is an Assistant Professor in Civil Engineering at Trinity College Dublin. He currently leads a number of projects that examine sustainable transport options, intelligent transport systems, carbon pricing, and renewable energy. He is author on more than 60 publications on a wide range of transportation topics. 